\title{
DIMENSIONES Y USOS DE LOS TÉRMINOS POESÍA, POEMA Y POÉTICA
}

\author{
DIMENSIONS AND USES OFTERMS POETRY, POEM AND POETIC
}

\section{Santos Conde Lucero ${ }^{I}$}

\section{RESUMEN}

"Poesia", "poema" y "poética" son términos conceptualmente diferentes, aunque se fundamentan en un principio común: el arte de la palabra. Es frecuente el uso de la palabra poesia para referirse a todo texto en verso, lo cual es incorrecto. El poema es sólo el medio del cual se valen los poetas para manifestar un sentimiento altamente intensificado y pretenden recibir la gracia de la poesía, muchas veces sin lograrlo. En cambio, la poesia no tiene forma, por lo tanto, resultaria imposible definirla. Su naturaleza está por encima de cualquier expresión artística. Una representación verbal en verso, aún estando cuidadosamente elaborada, no siempre puede catalogarse como poesía. Este caro atributo tampoco es su patrimonio exclusivo, pues, existen textos en prosa que tienen poesía, por ejemplo, Platero y Yo de Juan Ramón Jiménez.

Palabras clave: Poema, poesia, poética, poeta, lúdico, actores liricos, linea de tensión, motivos, asunto, tema, unidades temáticas.

\section{ABSTRACT}

Poetry,"poem"and poetic"are conceptually different terms, but are based on a common principle: the art of the word. It is frequent the use of the word poetry to refer to any text in verse, which is incorrect. The poem is only the means by which the poets apply to express a highly intensified feeling and claim to receive the grace of poetry, often without success. Instead, poetry has no form; therefore, it would be impossible to define. His nature is above all artistic expression. A verbal representation in verse, still being carefully crafted, cannot always be classified as poetry. This expensive attribute is also not its unique heritage because there are texts in prose with poetry; for example, Platero and I by Juan Ramón Jiménez.

Keywords: poem, poetry, poetic, poet, playful, lyrical actors, line voltage, grounds, subject, theme, thematic units.

\section{INTRODUCCIÓN}

El propósito del presente trabajo es precisar los términos conceptuales erróneamente utilizados en el ambiente académico por quienes se desempeñan como docentes de Lengua y Literatura, estudiantes y demás personas aficionadas a este campo.

Los docentes que enseñan literatura, los estudiantes que tienen que analizar un texto en verso, así como los aficionados al arte de la composición emplean el término poesía para referirse a un poema, no importando su calidad. Son tantas las frases que se suelen utilizar, por ejemplo, es común escuchar al maestro de aula, ante sus alumnos, "aprender la poesía", "recitar la poesía", "escribir una poesía", "leer una poesía", "traer una poesía", frases de esta naturaleza se usan con frecuencia y, casi, nadie repara en el asunto. Salvo algunas voces de expertos, de críticos que conocen ese campo, quienes, después de leer un poema, opinan, "qué mal trabajo", "no tiene poesía", "no está logrado", "falta consistencia", "es pura forma". También suelen haber aquellos conservadores que carecen de tacto para valorar con objetividad un texto en verso y no aceptan experimentos e innovaciones estéticas, entonces, recomiendan al autor que "se dediquen a otra cosa, menos a escribir poesía". Como se ve, existen controversias de todo tipo, como también ignorancia absoluta. Ante esta situación, se interroga, ¿Qué es poesía? ¿Qué hace que un texto en verso sea poético? ¿Qué debe hacer el creador para alcanzarla? Se sabe que el verdadero artista se desvela y va en su busca. A veces fracasa, pero es un bello fracaso. No se amilana. Insiste siempre. Respecto a las interrogantes, no conocemos aún respuestas definitivas, sino, sólo intentos y aproximaciones.

\footnotetext{
${ }^{1}$ Magister en Docencia Universitaria. Facultad de Educación, Comunicación y Humanidades. Universidad Nacional Jorge Basadre Grohmann. Correoelectrónico:conde_mayo@hotmail.com
} 
Iniciaremos la exposición citando algunos conceptos de poesía. Según Johannes Pfeiffer (1951:35), es el "arte que se manifiesta por la palabra". Pero el término "arte" no siempre garantiza la eficacia de un texto. Poesía es algo más que el puro arte. El mismo autor precisa que "la poesía no es distracción, sino concentración, no es sustituto de la vida sino iluminación del ser, es decir, no es claridad del entendimiento, sino verdad del sentimiento". Aquí sí, coincidimos, aunque más que iluminación, bien podría ser "revelación" y de hecho como única forma de expresar "la verdad del sentimiento".

En poesía no es suficiente una forma bella, sino una forma significativa. Tal orientación semántica tiene que ver con el juego de significados. Un poema también es un acto lúdico que el autor realiza. Él juega con el contenido. Su imaginación es poderosa y natural para realizar el desplazamiento de los significados de un objeto a otro, tan sólo con la fuerza de la fantasía, pues sabe que ésta es la única forma de trascender los límites de la razón. El artista logra su propósito cuando expresa sus ideas con absoluta libertad, aun más, con el empleo inusual del lenguaje. Muchos poemas ofrecen una forma brillante; pero no son nada significativos; la poesía viene entonces por el camino de la significación, surge del caos y de las confrontaciones que experimenta el creador, no el escribidor.

Dámaso Alonso, sobre este mismo tema, valora otro detalle: el ritmo. Señala que la poesía no se limita a las simples formas; el ritmo es la esencia de la poesía y es su única y verdadera realidad. Se entiende que no se refiere al ritmo externo de las formas, sino al ritmo interior, próximo a la música, que viene del oído y palpita en el corazón, tampoco es el redoble de un tambor de guerra, sino el pulso, la vibración del espíritu que se materializa en palabras, en imágenes, las cuales afectan a los órganos sensoriales. Estos son los sensores electrónicos que transmiten al cerebro y son capaces de hacer sentir las mismas emociones que experimenta el autor en el momento de escribir, en el receptor que lee o escucha aquella expresión.

Fernando Gómez Redondo coincide con la definición de Alonso. De manera más explícita, justifica que la poesía es "emoción convertida en ritmo" y también precisa que es una "experiencia (emotiva o intelectual) trascendida a belleza por el poder articulatorio de la palabra..." (Gómez, F. 1994:61).

Núñez Ramos Rafael, un poco más realista, señala que poesía es "creación lingüistica, una manera personal de nombrar el mundo y la implicación en él" (Nuñez, R. 1998:106). Esta idea nos consuela en algo, sobre todo, aquellos que pensamos que la escritura se puede enseñar, más no la poesía. Si nos detenemos en su afirmación, podemos entender que el artista trabaja con palabras, crea con palabras, inclusive crea las mismas palabras; crear significa "inventar" algo nuevo; si vemos el mundo como un caos, entonces tenemos el derecho de crear otro más armonioso y útil. Nosotros mismos, en lo posible, nos revelarnos en él. Nombrar las cosas, los seres, las situaciones con quienes se pueda convivir en paz, en armonía. Los grandes conflictos que motivan la recreación se hallan en este mundo.

La poesía, por lo tanto, implica algo más que "creación poética y métrica". Tal vez "creación" esté más cercana a la expresión "poesía", pues, deriva de un verbo de origen griego, que significa "crear", "hacer". Pero aún así, sigue siendo algo no precisable.

$\mathrm{El}$ poeta, antes que nada, es inventor, creador y hacedor no sólo del poema, sino también de los elementos que configuran el poema y del dibujo que lo sustenta, acaso de él mismo.

También, acerca de la poesía como juego, Rafael Núñez R. tiene una apreciación particular. La poesía, según este teórico, "constituye una forma de juego". El juego es una actividad libre y desinteresada que exige la satisfacción previa de las necesidades vitales.

Para jugar es preciso estar libre de este tipo de afanes, pues el juego no los colma; de manera que, al mismo tiempo, el juego es una manifestación de la libre voluntad del que juega hasta el punto de que nadie puede ser obligado a jugar: quien no quiere jugar no puede jugar. (Nuñez, R. 1998:32)

El juego exige una actitud, una situación, una disposición peculiar de manera que la conducta sea interesada sin que, el objeto inmediato al que se dirige tenga interés para el hombre, este acto, por analogía se puede aplicar al artista, al poeta verdadero.

Este mismo autor diferencia dos tipos de juegos: "un juego combinatorio que opera sobre los elementos sensoriales del lenguaje y un juego de imitación que opera con la relación entre el significado y la realidad, entre el signo y el mundo" (Nuñez, R. 1998: 48-49).

El poema no es la representación de la realidad como una fotografía, sino la representación recreada y transformada de esa realidad en otra, mejor dicho, en un mundo ficticio y en él los actores líricos intensifican un problema humano. El arte consiste en representar los hechos como si se tratara de la misma vida real. Lo que ofrece el autor no es su vivencia personal, tampoco tiene porque serlo. Más bien expresa la generalización de una experiencia vivida. La intención es que los lectores se comprometan con el problema, con el motivo generado a partir del tema que desarrolla.

Existen lectores que emotivamente se identifican tanto y se apropian del mensaje, como de algo suyo y lo repiten de memoria, sintiendo igual la 


\section{La Vida y la Historia}

Conde, S. Dimensiones y Usos de los términos Poesía, Poema y Poética.

experiencia dramatizada por tales actores.

Resulta también un error de parte del receptor cuando al término de la lectura de un poema declara: "el autor dice..." El poema no expresa la voz del poeta. Éste sí, maneja voces que no le pertenecen a él, sino a los protagonistas que intervienen en el discurso. El poema entonces no es una confesión a gritos del autor.

En cuanto a la ficción como mecanismo, los críticos coinciden en que esta es un juego por partida doble. Al respecto, Rafael Núñez explica:

... en primer lugar, porque todo juego lo es en alguna medida, ya que implica un universo cerrado, convencional $y$, en algunos aspectos, imaginarios; en segundo lugar, porque, como la literatura toda, pertenece a la clase de juego llamada mimicy (imitación), que consisten en convertirse uno mismo en un personaje ilusorio y comportarse como tal, en los que se juega a creer, a hacerse creer o a hacer creer a los demás que es alguien distinto de sí mismo. (Nuñez, R. 1998:49)

¿Cuál es la tarea del poeta, entonces? Susanne Laanger responde que la tarea es crear la imagen de sucesos vividos o sentidos, organizados de tal modo que constituyan una realidad experimentada pura y completamente, un trozo de "vida virtual", la cual hace que cada lector reaccione a su manera, pero que es percibida por la mayoría de la misma forma esencial como para funcionar comunicativa o simbólicamente. La configuración de los actores líricos que dramatizarán en un espacio también imaginariamente ambientado para la escenificación responde a esa necesidad de juego.

Jean - Marie Schaeffer (xxxx) sostiene que "la ficción es una termatización de la realidad según tal o cual de sus modalidades de manifestación".

Otra interrogante referente al acto creativo es. ¿Qué se entiende por creación interior y ejccución exterior? Crear no es más que inventar formas y figuras que toman cuerpo, ya sea en un poema, un cuento o una novela, según el tema de interés. Al respecto, Luis Juan Guerrero explica:

La plasmación de una obra de arte consiste, ante todo, en engendrar una "figura" o "forma" interior. Para ellas, el artista primero alcanza una configuración anímica o espiritual y luego la ejecuta, en tanto la instala en la realidad. De este modo, la producción de la obra se resuelve en la ejecución de signos físicos que sirven para exteriorizar una imagen mental, ya constituida de antemano, (Guerrero, L. 1957:160)

Aquellas figuras aludidas, aquellos actores líricos en poesía, son los portadores de un tipo de problema que con la fuerza creativa del poeta se intensifica; el buen lector descubre la línea de tensión y, desde un inicio, se interesa por la intriga, continuando en su desarrollo, luego alcanza el clímax, hasta que sucede el desenlace inesperado, feliz, trágico, agradable o desagradable, según la intención de quien lo concibió.

Referente a la imaginación de los poetas, George Santayana indica que existen posibles realidades humanas, pasiones exageradas, nuevas situaciones, aventuras extravagantes, entre otros hechos extraordinarios que pueden dominarnos a plenitud:

La imaginación crea con la misma facilidad que abstrae; observa, combina y simplifica, pero también sueña. Las síntesis espontáneas se produce en lo que no son promedios matemáticos de las imágenes que aquella recibe de los sentidos; son efectos de excitaciones difusas dejadas por las sensaciones en el cerebro. Estas excitaciones varian constantemente en sus varias reiteraciones, y en ocasiones toman una forma tal que el alma queda sorprendida con la visión intima de una belleza sin par. Si esta visión íntima es clara y fija, tenemos una inspiración estética, una vocación que nos induce a crear, y si también dominamos la técnica artística apropiada, nos apresuraremos a expresar esa inspiración, realizando así un ideal. Este ideal setá reconocido gradualmente como sumamente bello por la misma razón que, de haberse presentado en el mundo real, habría sido reconocido como sumamente bello el objeto, o sea porque expresando un tipo de forma conocido es decir, siendo propiamente un hombre, animal o vegetal-poseía en grado extraordinario los encantos directos que más subyugan nuestra atención. (Santayana, G. 1969:166)

Como se podrá deducir, el poema es un objeto lingüístico perceptible no sólo por el entendimiento, sino básicamente por los órganos sensoriales del los lectores. En términos de creación constituye el enunciado lírico, organizado en planos y facetas, no sólo de carácter gramatical, sino también retórico. Ahora bien, el hecho de intervenir en la escenificación los actores líricos supone que el discurso en verso está marcado por una línea de tensión que vendría a ser su diseño interior.

Respecto a la configuración de un poema, Gómez Redondo señala que un poema, con relación al que lo crea, es un filtro que contiene ciertos rasgos y ciertos elementos que funcionan de dos maneras: como dinamismo interior y como dinamismo exterior:

a) Dinamismo interior, cuando el poema va de fuera a dentro, es decir, cuando el poeta, sin tener una 
idea muy precisa de qué es lo que quiere decir, adecua su conciencia creadora a esas estructuras sígnicas y poemáticas, de modo que el poema se convierta en una manifestación de su sensibilidad poética, en una verificación de su actitud personal ante el mundo que le rodea, un mundo que es envuelto en esos procesos de conformación sígnica en los que acaba disolviendo sus límites y perfiles para obtener lo que el poeta logra ( $a$ veces porque lo quiere) conferirle; b) Dinamismo exterior cuando el poeta va de dentro a fuera, es decir, cuando es previo el sentimiento, la noción poética y el poema subrayan, con sus moldes y elementos formales, las ideas que van a ser cxpuestas. (Gómez, F. 1994:61$62)$.

El poema como unidad lingüística significativa, como signo complejo, no es un simple discurso objetivado con palabras, el valor estético es del todo y no de las partes. El texto en verso, en consecuencia, es autónomo. Una definición de esta naturaleza, necesita entender dos cosas, que puntualmente aclara Rafael Núñez:

1. Que las unidades lingüísticas, que constituyen signos completos con significados estables predeterminados en el código de la lengua, pierden esta condición para ser sólo partes de un signo más amplio.

2. Este signo más amplio es el poema como un todo, con relación a la cual los significantes y los significados de los términos son sólo partes dotadas de una energía significativa que sólo su posición en la totalidad permite liberar y orientar, es decir, tanto la forma fónica como el significado de un término son como un trazo o una mancha en un cuadro, cuyo valor depende menos de sus propiedades (el color de la mancha, la dirección del trazo, el significado convencional o la estructura fónica), que de las relaciones que contraen con las demás partes y con el todo; esta circunstancia se ve favorecida por el carácter no referencial de los signos artísticos. Por eso, la poesía no se puede traducir, ni el poema se puede decir con otras palabras...

El poema, pues, transforma el modo de ser y de actuar propio del lenguaje y lo hace de dos maneras:

a) Quebrantando las reglas que rigen su funcionamiento;

b) Conservando tales reglas pero superponiendo reglas propias. La primera rúbrica acoge todos los fenómenos de desvío; la segunda puede alcanzar una explicación unitaria apelando al principio de recurrencia de la función poética. (Nuñez, R. 1998:107-108)

Existen muchos medios utilizados por los poetas que la crítica los identifica como causantes de la desviación del orden regular del pensamiento, aunque tales creadores los emplean como procedimientos para la liberación de los sentidos y se hallan en todos los textos poéticos, antiguos y contemporáneos, están codificados como comparación, metáfora, animismo, imagen y símbolo. A nivel de construcción tenemos el hipérbaton y las frases ambiguas, todas ellas intencionalmente afectan al intelecto de los lectores, quienes, al simple contacto con sus órganos sensoriales, lo aceptan o, por el contrario, lo rechazan.

El poema externamente es una forma lingüística completa que, para leerlos, invita a los lectores a que pongan en juego sus competencias estéticas. Se caracteriza por su unidad y por la cohesión de su significado en función a un diseño individual.

Tal como observan algunos, la unidad semántica del poema se da por la permanencia de un tópico elegido. Este es el elemento focalizado al que se refieren la mayor parte de comentarios o predicados. A veces, un asunto es desglosado en otros menores, en fin, siendo el arte libre y abierto, pueden llevar a la inclusión de nuevos asuntos.

Es en ese enunciado poético, en ese mundo ficticio llamado poema, donde los actores líricos también imaginarios se desenvuelven y crean situaciones dramáticas que se intensifican en su desarrollo.

Un buen poema ofrece una coherencia global, aún resultando simple su diseño; en caso de ser complejo, la participación de los actores líricos exige que el número de asuntos seleccionados sea mínimo y la relación entre ellos, coherente. Los asuntos aún teniendo propósitos diferentes, incluso opuestos, se relacionan por recurrencia semántica. El tema, en consecuencia, aparece como el elemento catalizador. En el discurso, los asuntos se manifiestan por boca de cada actor lírico.

Sobre el tema, esta categoría semántica abstracta, mejor dicho, esta macroproposición genera los asuntos anteriormente mencionados, tales unidades temáticas, el poeta las secuencializa en el texto, no sólo por oposición, sino también mediante una analogía, repetición o ejemplificación, dependiendo de la intención de aquel.

Según Maurice Nédoncelle (1966:112), el poema "es el sentimiento que une sentimientos, el concepto que recoge conceptos. No lo creemos indeterminado, mientras que es capaz de suscitar indefinidamente la determinación".

Ahora bien, ¿es necesario el arte métrico? Una de las observaciones frecuentes de la crítica es que la poesía no siempre está presente en un poema, tampoco aquella es exclusividad de este tipo de manifestación artística. La estrofa y la métrica que son formas 


\section{La Vida y la Historia}

Conde, S. Dimensiones y Usos de los términos Poesía, Poema y Poética.

clásicas no necesariamente determinan lo poético. Como señala J. Peiffer:

...el metro es lo exterior; el ritmo, lo interior; el metro es la regla abstracta; el ritmo la vibración que confiere vida; el metro es el siempre, el ritmo el aquí y el hoy; el metro es la medida transferible e inconmensurable. (Pfeiffer, J. 1951:22)

En poesía, lo esencial es vivir las palabras "en toda su virginal plenitud de sentido y plasticidad"; la intuición se eleva sobre la comprensión, la imagen sobre el concepto, tal como precisa este mismo autor:

...en la medida en que la poesía es masa de sonido, lo esencial en ella es su fuerza plasmadora rítmico melódica; y que en cuanto a masa de sentido, lo que importa es su virtud proteica. La vibración rítmica y la resonancia melódica dan al lenguaje poético la posibilidad de expresar cierto hondo temple de ánimo; su articulación sintáctica y su significado objetivo le confieren la virtud de conjurar una figuración dinámicamente atemperada por un temple de ánimo. (Pfeiffer, J. 1951:31)

Finalmente, respecto a la poética, a diferencia del concepto de "poesía" y "poema", esta viene a ser la teoría de las formas artísticas. Dilthey W, la concibe como aquello que "aspira ser una técnica". Quienes se basan en este principio, pretenden descubrir las leyes artísticas universalmente válidas. Tales leyes desempeñan una doble función, primero, como reglas de creación y, segundo, como normas para la crítica.

Cada época ofrece una técnica determinada; sin embargo, aquella técnica no es particular, sino forma parte de las leyes generales y universalmente válidas. La poética más antigua y aún vigente es la propuesta de Aristóteles. A partir de sus postulados, se ha llegado a sostener que "el arte es el órgano más adecuado para comprender la vida".

La poética, al margen de su interés teórico, facilita los mecanismos de aproximación, necesarios para emjuiciar objetivamente una obra artística. Según señala Eugenio Pucciarelli:

... debe proporcionar al artista una técnica, un instrumento de trabajo, una disciplina; al crítico, una pauta adecuada para el análisis objetivo de las formas; al filólogo, un auxiliar para la interpretación, y al público interesado en la literatura, orientaciones seguras en medio del laberinto de creaciones heterogéneas y gustos incompatibles. (Dilthey, W. 1945:IX-X).

Dilthey, en uno de sus principios de su poética, plantea como única vía de acceso a la obra de arte, "la investigación psicológica de los procesos de creación y goce estéticos y el análisis objetivo e histórico de las creaciones artísticas". En este sentido analiza "la organización psíquica del poeta", se centra en el análisis del proceso interior de la creación y de sus condiciones psicológicas que experimenta el autor.

Señala que la vida anímica del creador se fundamenta en la imaginación y en el sentimiento. La imaginación se relaciona doblemente, primero, con la experiencia del poeta y, segundo, con los procesos psíquicos, que pueden ser intelectuales, afectivos y volitivos, por lo tanto, dice, de aquella experiencia del creador proviene la riqueza de su contenido, y de la energía con que procede en la creación del texto poético, de la vivacidad y de la animación con que crea, provienen, el brillo, el color y el relieve que todo objeto artístico como el poema debe tener. Dilthey arriba a las siguientes conclusiones:

No existe un concepto universalmente válido de lo bello. Hay, en cambio, un proceso de creación sujeto a leyes, que radica en la naturaleza humana y es aprensible en la estructura de la vida anímica. Su resultado, la obra de arte, engendra satisfacción en el creador y goce en el contemplador. A ella, a la obra de arte, llega el artista por un sistema de procedimientos, la técnica, que supone conciencia de los fines y posesión segura de los medios que permiten alcanzarlos. Existen, sin duda, principios de validez universal que regulan la impresión y el goce; pero la técnica misma sólo dispone de una validez relativa y está condicionada por el pueblo y la época. (Dilthey, W. 1945:XVI).

En cuanto a otros principios estéticos, Aristóteles sostiene que el objeto de la poesía es el hombre en acción, mientras que Dilthey manifiesta que la base de toda verdadera poesía es la vivencia:

... la vivencia, experiencia vivida, elementos anímicos de toda especie que entran en relación con ella. En tal relación pueden ser materiales directo para la creación del poeta todas las imágenes del mundo exterior. Toda operación de la razón que generaliza las experiencias, que ordena y acentúa su utilidad, sirve de igual modo a la labor del poeta. (Dilthey, W. 1945:45).

Las imágenes de la vida constituyen el suclo de donde la poesía extrae los elementos esenciales para su subsistencia.

\section{CONCLUSIONES}

Resulta imposible definir a la pocsía, por lo tanto, existe un mal uso de su concepto, al designar a 
todo poema como poesía. En un poema no siempre se halla la poesía.

El poema es la representación de un mundo ficticio y pretende ser semejante al mundo real; los protagonistas de aquel escenario virtual también son figuras imaginarias, inventadas por el poeta y son ellos quienes ayudan a intensificar el poema.

Un texto poético tiene un principio y tiene un final: la secuencia de las unidades temáticas expresadas en el discurso está articulada a partir de un diseño interior que sirve de base y sobre el cual se entreteje el lenguaje, formando niveles fonéticos, fonológicos, morfosintácticos, semánticos y planos o esferas de representación.

Sin embargo, para su comprensión, no es suficiente la explicación del inicio y del cierre del poema, tampoco es suficiente la determinación de cómo es su diseño interior, pues la localización del dibujo no garantiza el valor estético, tampoco, la identificación de los actores líricos que participan en el discurso. Al poema hay que medirlo y valorarlo a través de estos cuatro aspectos importantes: el sentido, sentimiento, tono e intención del autor.

El papel del lector consistirá en valorar la habilidad lingüística que ofrece el creador para organizar el poema y, por otra parte, también valorar la imaginación para representar las figuras que se desenvuelven en el texto. Ambos aspectos responden al ideal estético del poeta.

Un texto poético aparece objetivado con palabras cargadas de sentido, con frases que le dan relieve y con un tipo de perspectiva como diseño y sobre ella gira la representación simbólica. La unidad significativa de un poema entonces es alcanzada en función a los postulados que el creador tiene como ideal estético.

Finalmente, no es igual poesía que poema, del mismo que poética y poeta tienen otra denotación.

\section{REFERENCIAS BIBLIOGRÁFICAS}

DILTHEY, Wilhelm: Poélica. La imaginación del pocta. Las tres épocas de la estética moderna y su problema actual. Buenos Aires, Editorial Losada S.A. S.F. 1945

GEIGER, Moritz: Estética. Los problcmas de la estética. La estética fenomenológica. Buenos Aires, Biblioteca Argos s.f.

GÓMEZ REDONDO, Fernando: El lenguaje literario. Teoría y prúctica. Madrid, Ibérica Grafic S.L., Segunda edición. 1994.

GUERRERO, Luis Juan: Creación ejecución de la obra de arte. Estética de las potencias artísticas, Buenos Aires, Editorial Losada S.A. 1957.

KRAUZE, Ethel: Cómo acercarse a la poesía, México, Limusa Noriega Editores, Primera Edición 1992.

LOTMAN, YURI M: Estructura del lexto artístico, Madrid, Ediciones Istmo S.A. Primera Edición, 1988.

LUJÁN ATIENZA, Ángel I. Cómo se comenta un poema, Madrid, Edilorial SÏNTESIS S. A. Primera reimpresión, octubre, 2000.

MARCOS MARÍN, Francisco: El comentario lingüástico. Metodología y práctica, Madrid, ediciones Cáledra S.A., Quinta Edición, 1981.

NAVARRO DURÁN, Rosa: Comentar textos literarios, México, Pearson Educución, Primera reimpresión, 1998.

NEDONCELLE, Maurice: Introducción a la estética, Buenos Aires, Ediciones Troque S.A., 1966.

NÚNEZ RAMOS, Rafacl: Teoría de la litcratura y literatura comparada. La poesía, España, editorial síntesis, Primera Reimpresión, 1998.

PAZ, Octavio: El arco y la lira. México, Fondo de Cultura Económica, Sexta reimpresión, 1986

PFEIFFER, Johannes: La poesía. Mérico, Fondo de Cultura Económica, 1951.

SANTAYANA, George: El sentido de la belleza. Esbozo de una Leotía estética, Buenos Aires, Editorial Losada S.A., 1969.

VALVERDE. José María: La literatura. Qué era y qué es, Barcelona, Montesinos Editor S.A., Ediciones 1982. 